\title{
Eksotisisasi Kuliner Madura (Campur Lorjuk) dalam Film Aruna dan Lidahnya
}

\author{
Sri Wulandari \\ Universitas Gadjah Mada \\ Email: sri.wulandari19@mail.ugm.ac.id \\ * corresponding author
}

\section{Keywords: \\ Exoticization, Culinary culture, Food studies, Aruna dan Lidahnya, Film}

\begin{abstract}
Food existence has reached out all aspects of life. It also becomes the primary part of economic aspects, the sign of social differentiation, distinction, boundary, and contradiction. The interesting part of food is the changing discourse towards the food itself. The changing of the discourse emerged as the consequence of the transformation from the meaning of food as a practice into an aesthetic thing. A film entitled Aruna dan Lidahnya is Indonesian movie displaying the local food of several regions in Indonesia. It offers an attractive point of view in showing the culinary culture in Indonesia. This study aims to analyze the exoticization of Madura food (campur lorjuk) within Aruna dan Lidahnya. It employs the method of semiotic analysis. This study is showing that Madura cuisine (campur lorjuk) is imaged as "wild" food.
\end{abstract}

\begin{abstract}
ABSTRAK
Keberadaan makanan telah menyentuh segala aspek kehidupan dan merupakan fondasi setiap ekonomi, menandai perbedaan sosial, batasan, ikatan dan kontradiksi. Hal yang menarik dari makanan adalah perubahan wacana terhadap makanan itu sendiri. Perubahan wacana yang muncul sebagai akibat dari adanya pergeseran dalam melihat makanan sebagai persoalan kepraktisan menjadi persoalan estetika. Film Aruna dan Lidahnya merupakan film Indonesia yang membahas kuliner khas dari beberapa daerah. Film ini menawarkan cara pandang yang menarik mengenai budaya kuliner dalam konteks budaya kuliner Indonesia. Penelitian ini mengakaji mengenai eksotisisasi kuliner Madura dalam film Aruna dan Lidahnya. Metode yang digunakan dalam penelitian ini adalah metode analisis semiotika. Hasil penelitian menunjukkan bahwa kuliner Madura (campur lorjuk) dicitrakan sebagai kuliner "liar".
\end{abstract}

Copyright (C) 2019 Channel Jurnal Komunikasi. All right reserved.

\section{PENDAHULUAN}

Studi makanan (food studies) telah ada sejak lama, ledakan bidang studi tentang makanan dapat dilihat dari banyaknya penelitian interdisipliner tentang makanan; pertanian dan manusia, budaya dan pertanian, makanan dan tata cara makan, gastronomi, antopologi dan pangan dan lain-lain. Politisasi makanan dan perluasan gerakan sosial yang terkait dengan makanan telah meningkatkan kesadaran akan hubungan antara konsumsi dan produksi mulai dari bukubuku tentang pangan dan pertanian, memasak dan lain sebagainya. Tidak hanya buku, kini dunia perfilman pun khususnya Indonesia mulai mengangkat isu yang berkaitan dengan makanan, menawarkan cara pandang yang berbeda dalam melihat makanan, mengangkat kearifan lokal melalui kuliner dan sebagainya.

Beberapa film Indonesia yang bertemakan kuliner, diantaranya adalah Madre (2013), Tabula Rasa (2014), Filosofi Kopi (2015, 2017) dan Aruna dan Lidahnya (2018). Dari beberapa film yang telah disebutkan, menurut peneliti film Aruna dan Lidahnya menarik untuk dikaji lebih dalam karena menawarkan cara pandang yang menarik mengenai kuliner Madura yaitu campur lorjuk. Lebih lanjut Turner melihat makna film sebagai representasi dari realitas masyarakat bukan hanya sekedar sebagai refleksi dari realitas. Fisher dalam (Carole Counihan \& Esterik, 2013:3) mengatakan bahwa 
makanan menyentuh segala aspek kehidupan dan merupakan fondasi setiap ekonomi, menandai perbedaan sosial, batasan, ikatan dan kontradiksi. Maka menarik untuk mengkaji film yang menjadikan kuliner sebagai topik utamanya dikarenakan melalui kuliner kita bisa melihat bagaimana budaya ini mempengaruhi berbagai bidang kehidupan.

Chaney dalam Rahman (2016) mengatakan bahwa hal yang menarik dari makanan adalah mengenai perubahan wacana terhadap makanan itu sendiri. Perubahan wacana itu muncul sebagai akibat dari pergeseran dalam melihat makanan sebagai persoalan kepraktisan (practically) menjadi wujud persoalan estetika (aesthetics), yaitu suatu tampilan kompetensi sosial atau citarasa yang dianggap tinggi. Citarasa secara kultural dibentuk dan dikendalikan secara sosial. Sejalan dengan apa yang diungkapkan oleh Chaney terkait dengan citarasa terhadap makanan, pakar sosiologi makanan Stephen Mennel mengatakan bahwa hubungan citarasa dengan kebiasaan dan pengaruh lingkungan menunjukan sejauh mana pengaruh sosial budaya dalam membentuk citarasa seseorang atau masyarakat terhadap makanan di lingkungan di mana ia atau mereka hidup (Rahman, 2016:8). Selain itu, di mana kita makan, apa yang kita makan dan bagaimana cara kita menikmatinya menunjukkan identitas kita. Identitas menurut Chirs Barker dalam bukunya Cultural Studies adalah soal kesamaan dan perbedaan tentang aspek personal dan sosial, tentang kesamaan individu dengan sejumlah orang dan apa yang membedakan individu dengan orang lain (Syarifudin, 2017)

Penelitian-penelitian mengenai media, khususnya film telah banyak dilakukan. Akan tetapi sejauh pengetahuan saya masih belum ada kajian yang membahas tentang film Aruna dan Lidahnya tetapi ada penelitian yang mengkaji Aruna dan Lidahnya versi novel. Dalam artikel yang berjudul, Novel Aruna dan Lidahnya karya Laksmi Pamuntjak: Perspektif Gastrocriticism ditulis oleh Mareta menjelaskan bahwa Sastra dan kuliner berhubungan tidak hanya dalam hal yang bersifat material dan fisikal, seperti bagaimana tokoh-tokoh dalam karya sastra mengonsumsi dan menikmati makanan tetapi juga bersifat sosial kultural yaitu bagaimana tokoh-tokoh tersebut mengonstruksi identitas budaya dan prinsip hidup mereka melalui makanan (Artika, 2017). Berbeda dengan Mareta, penelitian selanjutnya ditulis oleh Selina Ching Chan dengan judul, Tea Cafes and The Hong Kong Identity: Food Culture and Hybridity. Selina dalam artikelnya membahas tentang kafe lokal/Caa Can Teng, bagaimana Caa Can Teng tersebut memiliki implikasi pada identitas Hong Kong. Ia berpendapat bahwa Caa Can Teng merepresentasikan budaya Hong Kong. Hibriditas di Caa Can Teng mencerminkan hubungan penduduk setempat di Hong Kong. Hibriditas yang ditemukan di Caa Can Teng melambangkan identitas Hong Kong sebagai keterikatan antara keragaman etnis Cina dan pascakolonial yang dicirikan oleh fleksibilitas, efisiensi, pilihan, dan keragaman (Chan, 2018).

Peneliti tertarik untuk mengkaji lebih dalam mengenai eksotisisasi kuliner Madura (campur lorjuk) dalam film Aruna dan Lidahnya. Barry berpendapat bahwa eksotisisasi merupakan salah satu aspek yang menjadi perhatian utama dalam kajian pascakolonial (Suwondo, 2012)bahasa, indentitas, dan resistensi terhadap kekuasaan kolonial ditinjau dari perspektif pascakolonial. Dari pembahasan yang dilakukan diperoleh hasil bahwa dalam novelnovel karya Suparto Brata tampak jelas bahwa kekuasaan kolonial (Belanda dan Jepang. Eksotisisme sebagai sebuah bentuk khas dari persepsi estetis sebuah pihak yang menjadikan seseorang, objek dan tempat sebagai liyan. Seperti yang sudah diketahui bahwa istilah estetis berasal dari kata estetika yang berasal dari bahasa Yunani aistesis yang mengacu pada persepsi indra dalam pengertian yang paling umum. Dengan demikian, pengalaman estetika sebagai penghubung yang masuk akal dengan dunia luar (the world outside) (Kuehn, 2014). Dalam buku Food and Culture, Heldke berpendapat bahwa kebaruan adalah hal yang menarik bagi petualang kuliner karena menandai keberadaan yang eksotis, di mana eksotis dipahami tidak hanya "tidak lokal" tetapi juga "sangat tidak biasa" (excitingly unusual). Pada giliranya eksotis digunakan untuk mengindikasikan keaslian. Makanan eksotis disebut sebagai otentik justru karena keanehannya dan kebahurannya (Heldke, 2013). Sedangkan, Segalen menyatakan bahwa eksotisisme merupakan gagasan tentang perbedaan, persepsi tentang keragaman, pengetahuan bahwa sesuatu itu berbeda dari diri sendiri dan kekuatan Eksotisme tidak lain adalah kemampuan untuk membayangkan atau berangan-angan (Segalen, V., 2002). Eksotisisme mengacu pada cara khusus dalam menjadikan orang dan hal-hal lain sebagai liyan.

Dalam film Aruna dan Lidahnya, keinginan untuk citarasa yang baru, tekstur baru, resep baru dan gaya makan yang baru mengirim Aruna dan teman-temannya sebagai petualang kuliner untuk menjelajahi kuliner dari kota lain yang jauh dari Jakarta yaitu salah satunya adalah kuliner Madura. Tindakan Aruna merupakan upaya untuk mengalami apa yang disebut dengan makanan "eksotis". Bagi para petualang kuliner, daya pikat dan daya tarik masakan semacam itu sering kali berasal dari sesuatu yang tidak biasa dan aneh. Berangkat dari isu tersebut, film Aruna dan Lidahnya digunakan sebagai pintu masuk untuk menganalisis eksotitasi terhadap kuliner Madura. Penelitian ini mencoba mengkaji bagaimana eksotisisasi kuliner Madura dalam film Aruna dan Lidahnya.

\section{METODE PENELITIAN}

Penelitian ini merupakan penelitian deskriptif kualitiatif yaitu sebuah penelitian dengan menggunakan data dan menghasilkan hasil penelitian yang berupa kata-kata dan gambar. Objek kajian dalam penelitian ini adalah film Aruna dan Lidahnya (2018) dengan memilah-milah elemen yang terkait dengan eksotisisasi kuliner Madura. Elemen-elemen tersebut meliputi audio dan visual. Beberapa istilah yang berkaitan dengan film dan yang digunakan dalam penelitian 
ini adalah shot, scene, dan sequence. Shot merupakan rangkaian gambar hasil rekaman kamera. Shot dirangkai ke dalam scene. Scene merupakan satu tindakan berkelanjutan dan umumnya terjadi di satu lokasi. Sedangkan sequence adalah kumpulan scene yang saling terkait. Sequence bisa berlangsung lebih dari satu tempat/setting (Johns, 2017).

Beberapa aspek gambar bergerak seperti film, televisi dan video juga dapat menggunakan terminologi interpretasi komposisi. Namun untuk gambar bergerak memerlukan seperangkat istilah lebih lanjut untuk mendeskripsikan kualitas dinamisnya. Monaco, 2009, menawarkan istilah yang berkaitan dengan gambar bergerak yaitu mise-en-scéne dan montage. Mise-en-scéne merupakan hasil dari keputusan tentang apa yang akan di potret (shot) dan cara memotretnya. Sedangkan montage merupakan istilah lain yang berkaitan dengan komposisi gambar bergerak (film), (Rose, 2016). Interpretasi komposisi sangat berguna sebagai tahap pertama untuk memahami gambar (baik gambar diam maupun gambar bergerak). Maka dari itu, interpretasi komposisi perlu dikombinasikan dengan metodologi lain untuk mengekplorasi bagaimana film membawa makna (carry meanings). Oleh karena itu, interpretasi komposisi dalam hal ini skema mise en scene dan montage dari Monaco, saya kombinasikan dengan semiotika.

Tahap selanjutnya pengumpulan data. Pengumpulan data dilakukan dengan melakukan pengamatan langsung atas teks film dari segi visual dan audio. Pencatatan dilakukan dengan mengambil cuplikan gambar dari film dan mencatat dialog-dialog yang terkait dengan eksotisisasi kuliner Madura. Data ini nantinya akan peneliti deskripsikan dan dialogkan untuk melihat bagaimana eksotisisasi kuliner Madura dalam film Aruna dan Lidahnya. Analisis dilakukan terhadap data yang diperoleh dengan menggunakan metode semiotika Roland Barthes. Barthes menandai bahwa segala macam bentuk semiotika mendalilkan suatu relasi diantara dua istilah yaitu penanda dan petanda. Mitos adalah sebuah sistem semiotika urutan kedua (Strinati, 2016). Hal ini menjelaskan bahwa mitos bersandar pada tanda-tanda dalam sistem urutan pertama lainya seperti bahasa agar dapat melibatkan diri dalam proses penandaan tersebut. Sistem tanda yang pertama sebagai denotasi, sedangkan makna yang diperoleh dari denotasi disebut sebagai konotasi. Selanjutnya, perkembangan dari makna konotasi disebut sebagai mitos.

\section{HASIL DAN ANALISIS}

\section{A. Sinopsis Film Aruna dan Lidahnya}

Aruna dan Lidahnya merupakan film Indonesia dengan genre drama yang di produksi oleh Palari Films dan disutradarai oleh Edwin, Titien Wattimena dan Laksmi Pamuntjak selaku penulis serta Meiske Taurisia dan Muhammad Zaidy sebagai produser. Film dengan durasi 106 menit ini merupakan adaptasi lepas dari novel karya Laksmi Pamuntjak dengan judul yang sama. Novel Aruna dan Lidahnya dirilis pada tahun 2014 sedangkan film Aruna dan Lidahnya sendiri dirilis pada 27 September 2018.

Aruna dan Lidahnya bercerita tentang seorang ahli wabah (ahli epidemologi) bernama Aruna Rai, di perankan oleh Dian Sastrowardoyo mendapat tugas menyelidiki kasus flu burung di beberapa tempat di Indonesia, meliputi Surabaya, Pamekasan, Singkawang dan Pontianak. Pada saat yang sama, sahabatnya Bono di perankan oleh Nicholas Saputra dan Nad di perankan oleh Hannah Al Rashid, bergabung dengan Aruna dan pergi melakukan petualangan kuliner. Bono merupakan koki profesional yang ingin menemukan resep kuliner otentik Indonesia. Sedangkan Nad merupakan kritikus kuliner sekaligus penulis buku mengenai kuliner. Tanpa diduga, perjalanan bisnis menyatukan kembali Aruna dengan mantan rekan kerjanya yang merupakan dokter hewan yaitu Farish di perankan oleh Oka Antara.

Keempat tokoh tersebut terlibat dalam percakapan intim sambil menikmati berbagai hidangan kuliner khas Indonesia. Keinginan Aruna dan teman-temannya untuk menemukan citarasa yang baru, tekstur baru, resep baru dan gaya makan yang baru mengirim Aruna dan teman-temannya sebagai petualang kuliner untuk menjelajahi kuliner khas dari daerah lain di Indonesia. Perjalanan mereka dibumbui oleh persahabatan dan problematika orang-orang berusia 30-an.

\section{B. Denotasi dan Konotasi pada Sekuens Campur Lorjuk}

Beberapa istilah yang berkaitan dengan film dan yang digunakan dalam penelitian ini adalah shot, scene dan sequence/sekuens. Shot merupakan rangkaian gambar hasil rekaman kamera. Shot dirangkai ke dalam scene. Scene merupakan satu tindakan berkelanjutan dan umumnya terjadi di satu lokasi. Sedangkan sequence adalah kumpulan scene yang saling terkait. Sekuens bisa berlangsung lebih dari satu tempat/setting (Johns, 2017). Sekuens ini menampilkan Aruna, Nad, Bono dan Farish pergi tempat makan (warung). 


\begin{tabular}{|c|c|c|}
\hline \multirow[t]{2}{*}{ Visual } & \multicolumn{2}{|l|}{ Audio } \\
\hline & Narasi & Musik \\
\hline shot 4 & $\begin{array}{l}\text { Bono :Satu hari masih bagus? dan } \\
\text { Cuma ada di Madura? di tempat lain gak } \\
\text { ada? } \\
\text { Penjual :Iya, soalnya orang sini } \\
\text { khasnya kan gini, campur lorjuk } \\
\text { Nad : Hmmm } \\
\text { Bono : Wow } \\
\text { Nad : Seharusnya ini lo jadiin menu } \\
\text { di restoran lu Bon tapi presentasinya } \\
\text { bagusin dikit. } \\
\text { Bono : Setuju gua. Gimana? } \\
\text { menghibur banget kan rasanya. Ini } \\
\text { mustinya ada di restoran, dimana } \\
\text { yang dateng itu orang-orang yang lagi } \\
\text { bersedih. } \\
\text { Aruna : Apa mungkin karena gua abis } \\
\text { di jutekin sama orang puskesmas ya? } \\
\text { Bono : Gak mungkin. Gak mungkin } \\
\text { lo gak suka. Ini ada yang salah sama } \\
\text { lidah lo. }\end{array}$ & - \\
\hline
\end{tabular}

Tabel 1. Tanda verbal \& non-verbal

Penanda dalam scene ini merujuk pada tempat makan jenis warung. Wanita meracik campur lorjuk untuk dihidangkan kepada Bono. Wanita tidak memakai seragam, tangan tidak bungkus dengan plastik, makanan tidak sepenuhnya dalam keadaan tertutup, ukuran bangunan yang cukup kecil dengan cat tembok dengan beragam warna yang mencolok, nama warung ditempelkan di kaca jendela $\left(\mathrm{Sd}_{1}\right)$ (shot 2). Sekumpulan penanda tersebut mengindikasikan 'sederhana', 'tidak bersih', 'khas'. Adegan dalam scene ini ingin menunjukkan bahwa kuliner khas daerah yang patut dikunjungi ialah warung sederhana, di pinggir jalan dengan kebersihan warung tidak terlalu diperhatikan, panci tempat merebus lorjuk dan kompor yang tampak kotor (shot 1).

Bentuk lain yang menjadi indikasi adanya praktik eksotisme yang dilakukan Aruna dan teman-temanya dapat dilihat pada shot 3, Bono berdiri di depan pintu masuk, memegang mangkok berisi campur lorjuk. Bagian ini cenderung menciptakan makna 'kekuasaan'. Bono menganggap dirinya sebagai pengunjung yang berbeda (superior) dalam budaya yang bukan miliknya sehingga Bono merasa seolah-olah memiliki kekuasaan di tempat tersebut. Pintu mengasosiasikan batas antara wilayah kekuasaan seseorang terhadap dunia luar.

Bono berada di dalam warung tepat dipintu mengindikasikan bahwa telah memiliki kekuasaan di tempat tersebut. Aruna dan Nad berdiri tepat di depan Bono dibatasi pintu bagian bawah yang tertutup, kode non-verbal ini menandai bahwa Aruna, Nad dan Farish menjaga jarak dengan yang mereka anggap eksotis. Alasan mereka menjaga jarak bisa jadi dikarenakan merasa bahwa tempat tersebut tidak nyaman, merasa tidak aman. Makna 'tidak aman', 'tidak nyaman' tampak dalam kode non-verbal yang ditunjukan Farish, menjaga jarak dengan yang lain, berdiri dengan menyilangkan kedua tangan di depan dada, cupit hidung ditarik ke atas disertai mulut tertutup rapat, sudut bibir naik merupakan gerak isyarat tubuh yang mengindikasikan hal yang tidak menyenangkan.

Berbeda dengan Bono yang berprofesi sebagai koki. Petanda yang menunjukan bahwa Bono berada di dalam warung, berinteraksi dengan penjualnya serta memegang mangkok dan didukung tuturan menghibur banget kan rasanya. Ini mustinya ada di restoran, dimana yang dateng itu orang-orang yang lagi bersedih, mengonotasikan 'menghibur', 'kesedihan'. Mengasosiasikan bahwa campur lorjuk merupakan kuliner dengan rasa yang menghibur untuk orang yang sedih. Kata 'menghibur' jika dikaitkan dengan adegan awal pada sekuens ini akan membentuk serangkaian makna bahwa kuliner dengan bahan yang unik serta cara pengolahan yang 'liar' adalah hal yang menarik untuk dijadikan 'tontonan', sehingga mampu 'menghibur' yang lagi bersedih. Secara spesifik campur lorjuk diidentikkan dengan kesedihan.

\section{Eksotisisasi Campur Lorjuk}

Eksotisisasi secara sederhana didefinisikan sebagai suatu cara dalam menjadikan hal yang tidak eksotis menjadi eksotis. Maka dalam proses tersebut ada beberapa kriteria yang menjadi indikator eksotisisasi. Kriteria eksotisisasi tradisional ialah keterasingan, ketidakfamiliaran, kekaguman, unik/khas/otentik, dan kesatuan. Kriteria tersebut dipraktikan oleh diri (pihak yang merasa dirinya superior) yang kemudian menginferiorkan orang, budaya maupun hal 
lainnya dan menjadikannya sebagai liyan. Pada sekuens campur lorjuk, adegan diawali dengan menampilkan pengolahan lorjuk dengan cara direbus hidup-hidup dalam air mendidih sehingga tampak lorjuk yang mengeliat (shot 1). Beberapa budaya di Indonesia masih menganggap pengolahan bahan makanan hewani dalam keadaan hidup masih merupakan hal yang tidak lazim, dianggap kejam dan menggelikan bahkan menjijikkan. Akan tetapi dalam film Aruna dan Lidahnya, hal tersebut dianggap sebagai suatu keuunikan yang menarik.

Menyantap hewan hidup-hidup sejatinya telah menjadi tradisi kuliner di beberapa negara di Asia, terutama di Jepang, Cina dan Korea. Dikatakan tradisi, karena selain dikonsumsi oleh masyarakat lokal, hidangan tersebut juga diperjualbelikan di berbagai restoran. Berbeda dengan Jepang, Cina dan Korea, di Indonesia tradisi kuliner semacam itu masih dianggap hal yang tidak biasa. Seperti halnya pengolahan lorjuk direbus dalam keadaan hidup. Adegan saat lorjuk menggeliat menandakan 'keliaran' (shot 1). Lorjuk dicitrakan sebagai kuliner 'liar', hal itulah yang membuat Aruna dan teman-temannya menggagumi kuliner khas Madura campur lorjuk. Tuturan verbal, iya, soalnya orang sini khasnya kan gini, campur lorjuk mengindikasikan bahwa bahan utama lorjuk hanya ada di Madura tidak mungkin ada di Jakarta maupun tempat lainnya. Keterasingan, ketidakfamiliaran serta ke-khasan campur lorjuk bagi Aruna dan teman-temannya ditunjukkan melalui penanda-penanda tersebut.

Sedangkan persepsi estetis Aruna dan teman-temannya terhadap lorjuk, ditandai melalui tuturan dengan penekanan intonasi pada kata LORJUK RUN, LORJUK!; LORJUK RIS, LORJUK!. Perulangan kata lorjuk pada beberapa adegan ditujukan untuk mengarahkan perhatian penonton pada kata tersebut. Penekanan intonasi dan perulangan pada kata lorjuk menunjukkan bahwa kuliner lorjuk adalah kuliner yang harus dikunjungi saat datang ke Madura. Sedangkan konotator 'kekaguman' adalah tersenyum lebar dengan bibir terkatup, mata terbuka lebar (shot 4) yang diikuti kode verbal hmm dan wow. Penanda-penanda tersebut merujuk pada bentuk ekspresi dari kekaguman. Hal ini juga diperkuat melalui tuturan, campur lorjuk: menghibur banget kan rasanya. Ini mustinya ada di restoran, dimana yang dateng itu orang-orang yang lagi bersedih.

Kriteria selanjutnya yang mengindikasikan adanya eksotisisasi adalah kesatuan. Artinya Aruna dan temantemanya melakukan upaya untuk menghilangkan keanehan dari campur lorjuk dengan cara menyesuaikan kuliner campur lorjuk berdasarkan standar/aturan penyajian makanan di restoran Jakarta (makanan kelas menengah atas). Hal ini tampak melalui kode verbal, seharusnya ini lo jadiin menu di restoran lu Bon tapi presentasinya bagusin dikit. Mengindikasikan bahwa campur lorjuk bagi Nad dan Bono merupakan sesuatu yang mengagumkan dari segi bahan dan rasanya akan tetapi dari segi tampilan dianggap tidak memenuhi kualifikasi untuk dijadikan salah menu di restorannya, kuliner tersebut akan dianggap layak disajikan apabila dilakukan perubahan pada bagian-bagian tertentu. Misalnya dari segi presentasi makanan dan bahan dasar/utamanya.

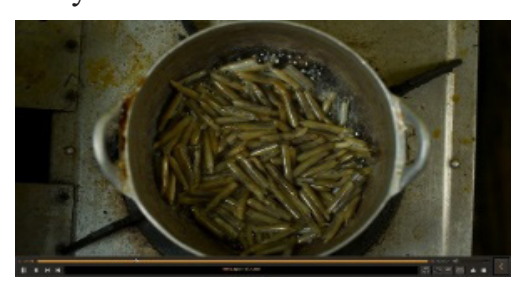

shot 1

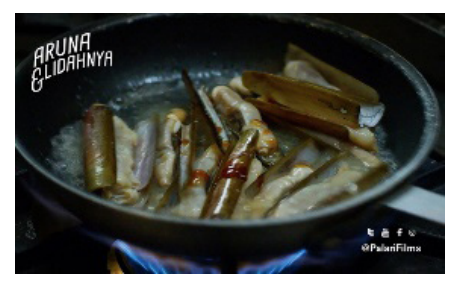

shot 5

Modifikasi yang dilakukan Bono mengindikasikan adanya upaya untuk menyeragamkan perbedaan. Shot 5 (pengolahan campur lorjuk di Jakarta) dan shot 1 (pengolahan campur lorjuk di Madura) merupakan penanda yang mengindikasikan adanya upaya yang dilakukan Bono untuk 'menjinakan' kuliner campur lorjuk yang dianggapnya 'liar'. Perbedaan visualisasi pengolahan, lorjuk: lorjuk direbus dalam keadaan hidup, tampak lorjuk menggeliat, panci dan kompor tampak kotor (shot 1). Sedangkan shot 5 menampilkan kerang batu diolah tetapi tampak tidak menggeliat (mengindikasikan bahwa kerang batu tersebut diolah dalam kondisi mati), alat masak dan kompor bersih. Perlu diketahui bahwa pada saat balik ke Jakarta, untuk kuliner campur lorjuk, Bono mengganti nama kuliner tersebut menjadi sup lorjuk dan bahan utamanya yaitu lorjuk diganti dengan kerang batu. Serangkaian penanda tersebut menjelaskan bahwa Bono berusaha 'menjinakkan' kuliner yang dianggap 'liar' dianggap layak dikonsumsi dan dihidangkan baik dari segi rasa, pemilihan bahan baku, pengolahan, penyajian dan sebagainya.

Pelabelan kuliner campur lorjuk sebagai sesuatu yang 'liar' bukanlah tanpa alasan. Jika ditelusuri lebih jauh, hal ini berawal dari kondisi geografis yang dimiliki Madura berupa lahan tandus, orang Madura lebih banyak menggantungkan hidup pada laut sehingga mereka pun berpola kehidupan bahari yang penuh tantangan. Inilah yang kemudian melahirkan perilaku sosial yang bercirikan keberanian tinggi, menjunjung tinggi martabat dan harga diri, berjiwa keras, dan ulet dalam hidup. Tak mengherankan jika dalam sikap dan perilaku sosial mereka itu tumbuh harga diri yang kadang-kadang berlebihan dan mengundang munculnya konflik. Oleh karena itu, tindak kekerasan seolah-olah juga lekat dengan pribadi orang Madura. Makna 'liar' yang ditunjukkan melalui pengolahan campur lorjuk seolah-olah mereproduksi stereotipe negatif mengenai masyarakat Madura yang diidentikkan dengan kekerasan, terbelakang, kasar dan sebagainya. Stigma 
sosial tentang masyarakat Madura yaitu keterbelakangan dan kekerasan. Kekerasan seakan menjadi atribut yang melekat di pundak masyarakat Madura. Sebagian besar masyarakat yang tinggal di luar Madura, mencitrakan masyarakat dan kebudayaan Madura dengan sikap serba sangar, mudah menggunakan senjata dalam menyelesaikan masalah (Dartiningsih, 2015).

\section{KESIMPULAN}

Kajian terhadap eksotisisasi kuliner Madura dalam hal ini adalah campur lorjuk dalam film Aruna dan Lidahnya menunjukan bahwa pertama, eksotisisasi budaya kuliner bukan kulinernya yang eksotis tetapi proses seseorang yang menjadikan makanan yang tidak eksotis tersebut menjadi eksotis. Hal ini lah yang dipraktikan oleh Aruna dan temantemanya terhadap kuliner Madura yaitu campur lorjuk. Hubungan yang terjadi diantara mereka merupakan hubungan dominasi dan subordinasi yang dimana Aruna dan teman-temannya memposisikan diri sebagai pihak yang dominan, aktif dan superior. Petualangan kuliner Aruna dan teman-temannya berpengaruh dalam membentuk selera dan citarasa mengenai kuliner daerah.

Kedua, kode audio maupun visual yang terdapat dalam film ini menjadikan kuliner campur lorjuk sebagai sesuatu yang mengagumkan dan tidak mudah dilupakan. Maksudnya ialah kuliner Madura tersebut akan diingat, hanya saja ingatan yang mereka ciptakan ialah ingatan bahwa kuliner Madura eksotis yang 'liar'. Terakhir, film Aruna dan Lidahnya yang mengangkat isu mengenai keragaman kuliner daerah di Indonesia salah satunya kuliner Madura dengan tujuan ingin membangun kembali wacana mengenai kuliner lokal, kearifan lokal dan sebagainya. Akan tetapi yang terjadi justru menciptakan wacana baru mengenai kuliner khas Madura yang eksotis merupakan kuliner yang 'liar'. Hal ini seolaholah mereproduksi stereotipe negatif mengenai masyarakat Madura dengan menciptakan wacana bahwa kuliner khas Madura 'liar' cocok dengan masyarakatnya yang keras, kasar dan sebagainya. Keliaran campur lorjuk digunakan untuk melegitimasi stereotipe negatif mengenai masyarakatnya.

\section{DAFTAR PUSTAKA}

Artika, M. D. (2017). Novel Aruna dan Lidahnya Karya Laksmi Pamuntjak: Perspektif Gastrocriticis. BAPALA, 4(1). Retrieved from https://jurnalmahasiswa.unesa.ac.id/index.php/bapala/article/view/19112

Chan, S. C. (2018). Tea cafés and the Hong Kong identity: Food culture and hybridity. China Information, 0920203X1877340. https://doi.org/10.1177/0920203X18773409

Counihan, Carole, \& Esterik, P. V. (2013). Food and Culture (3rd ed.). New York: Routledge.

Dartiningsih, B. (2015). Media dan Stereotipe terhadap Etnis Madura. In Surokim (Ed.), MADURA: Masyarakat, Budaya, Media, dan Politik (1st ed.). Madura: Puskakom Publik bekerjasama dengan Penerbit Elmatera.

Edwin. (2018). Aruna dan Lidahnya. Jakarta: Palari Films.

Heldke, L. (2013). Food and Culture. In Carol Counihan \& P. Van Esterik (Eds.), Food and Culture (3rd ed.). https://doi. org/10.4324/9780203079751

Johns, K. (2017). The Difference between Scenes, Sequences, and Chapters. Retrieved from http://www.kevintjohns. com/2017/03/20/scenes-sequences-chapters/

Kuehn, J. (2014). Exoticism in 19th-century literature. Library British. Retrieved from https://www.bl.uk/romantics-andvictorians/articles/exoticism-in-19th-century-literature

Monaco, J. (2009). How To Read A Film (4th ed.). Retrieved from http://www.oup.com

Rahman, F. (2016). Rijsttafel - Budaya Kuliner Indonesia di Indonesia Masa Kolonial 1870-1942 (1st ed.). Jakarta: PT. Gramedia Pustaka Utama.

Rose, G. (2016). Visual Methodologies - An Intoduction to Researching with Visual Materials (4th ed.). London: SAGE Publications.

Segalen, V. (2002). Essay on exoticism (Y. Schlick, Ed.). Durham: Duke University Press.

Strinati, D. (2016). Popular culture: Pengantar Menuju Teori Budaya Populer. Yogyakarta: Narasi.

Suwondo, T. (2012). Eksotisme, Bahasa, Identitas, Dan Resistensi Dalam Novel Indonesia Karya Suparto Brata: Pembacaan Pascakolonial. ATAVISME, 15(2), 147-162. https://doi.org/10.24257/atavisme.v15i2.56.147-162

Syarifudin, M. (2017). Konstruksi identitas dan ruang publik jamaah Maiyah Bang Bang Wetan Surabaya. DigitalLibrary UIN Sunan Ampel, 27. Retrieved from digilib.uinsby.ac.id 